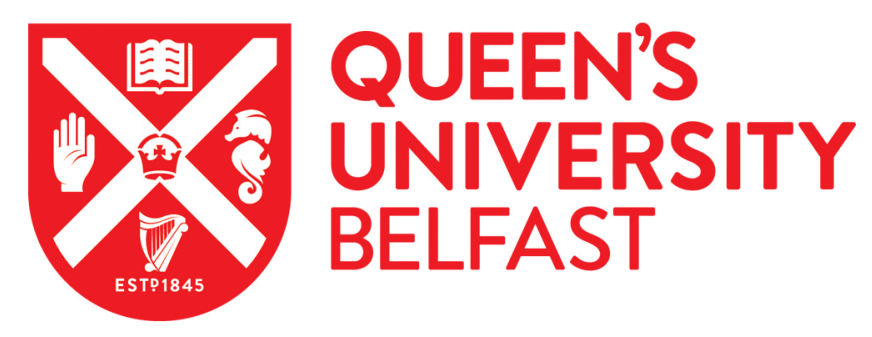

\title{
Consistent effects of consumer species loss across different habitats
}

Mrowicki, R. J., Maggs, C. A., \& O'Connor, N. E. (2015). Consistent effects of consumer species loss across different habitats. Oikos, 124(12), 1555-1563. https://doi.org/10.1111/oik.02138

\author{
Published in: \\ Oikos
}

\section{Document Version:}

Peer reviewed version

Queen's University Belfast - Research Portal:

Link to publication record in Queen's University Belfast Research Portal

\author{
Publisher rights \\ Copyright 2015 The Authors. Oikos Copyright 2015 Nordic Society Oikos
}

This is the accepted version of the following article: Mrowicki, R. J., Maggs, C. A. and O'Connor, N. E. (2015), Consistent effects of consumer species loss across different habitats. Oikos. doi: 10.1111/oik.02138, which has been published in final form at http://onlinelibrary.wiley.com/doi/10.1111/oik.02138/abstract

\section{General rights}

Copyright for the publications made accessible via the Queen's University Belfast Research Portal is retained by the author(s) and / or other copyright owners and it is a condition of accessing these publications that users recognise and abide by the legal requirements associated with these rights.

\section{Take down policy}

The Research Portal is Queen's institutional repository that provides access to Queen's research output. Every effort has been made to ensure that content in the Research Portal does not infringe any person's rights, or applicable UK laws. If you discover content in the Research Portal that you believe breaches copyright or violates any law, please contact openaccess@qub.ac.uk. 


\section{OIKOS}

\section{CONSISTENT EFFECTS OF CONSUMER SPECIES LOSS ACROSS DIFFERENT HABITATS}

\begin{tabular}{|c|c|}
\hline Journal: & Oikos \\
\hline Manuscript ID: & OIK-02138.R1 \\
\hline Wiley - Manuscript type: & Research \\
\hline Date Submitted by the Author: & $\mathrm{n} / \mathrm{a}$ \\
\hline Complete List of Authors: & $\begin{array}{l}\text { Mrowicki, Robert; Queen's University Belfast, School of Biological Sciences } \\
\text { Maggs, Christine; Queen's University Belfast, School of Biological Sciences; } \\
\text { Queen's University Belfast, School of Biological Sciences } \\
\text { O'Connor, Nessa; Queens University Belfast, Biological Sciences }\end{array}$ \\
\hline Keywords: & species loss, algae-grazer interactions, benthic \\
\hline Abstract: & $\begin{array}{l}\text { Our knowledge of the effects of consumer species loss on ecosystem } \\
\text { functioning is limited by a paucity of manipulative field studies, particularly } \\
\text { those that incorporate inter-trophic effects. Further, given the ongoing } \\
\text { transformation of natural habitats by anthropogenic activities, studies } \\
\text { should assess the relative importance of biodiversity for ecosystem } \\
\text { processes across different environmental contexts by including multiple } \\
\text { habitat types. We tested the context-dependency of the effects of } \\
\text { consumer species loss by conducting a 15-month field experiment in two } \\
\text { habitats (mussel beds and rock pools) on a temperate rocky shore, } \\
\text { focussing on the responses of algal assemblages following the single and } \\
\text { combined removals of key gastropod grazers (Patella vulgata, P. } \\
\text { ulyssiponensis, Littorina littorea and Gibbula umbilicalis). In both habitats, } \\
\text { the removal of limpets resulted in a larger increase in macroalgal richness } \\
\text { than that of either L. littorea or G. umbilicalis. Further, by the end of the } \\
\text { study, macroalgal cover and richness were greater following the removal of } \\
\text { multiple grazer species compared to single species removals. Despite } \\
\text { substantial differences in physical properties and the structure of benthic } \\
\text { assemblages between mussel beds and rock pools, the effects of grazer } \\
\text { loss on macroalgal cover, richness, evenness and assemblage structure } \\
\text { were remarkably consistent across both habitats. There was, however, a } \\
\text { transient habitat-dependent effect of grazer removal on macroalgal } \\
\text { assemblage structure that emerged after three months, which was } \\
\text { replaced by non-interactive effects of grazer removal and habitat after } 15 \\
\text { months. This study shows that the effects of the loss of key consumers } \\
\text { may transcend large abiotic and biotic differences between habitats in } \\
\text { rocky intertidal systems. While it is clear that consumer diversity is a } \\
\text { primary driver of ecosystem functioning, determining its relative } \\
\text { importance across multiple contexts is necessary to understand the } \\
\text { consequences of consumer species loss against a background of } \\
\text { environmental change. }\end{array}$ \\
\hline
\end{tabular}


Page 1 of $34 \begin{aligned} & \text { Oikos } \\ & \qquad \begin{array}{l}\hline \text { SCHOLARONE } \\ \hline\end{array} \\ & \text { Manuscripts }\end{aligned}$

Page 1 of $34 \begin{aligned} & \text { Oikos } \\ & \qquad \begin{array}{l}\hline \text { SCHOLARONE } \\ \hline\end{array} \\ & \text { Manuscripts }\end{aligned}$

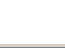
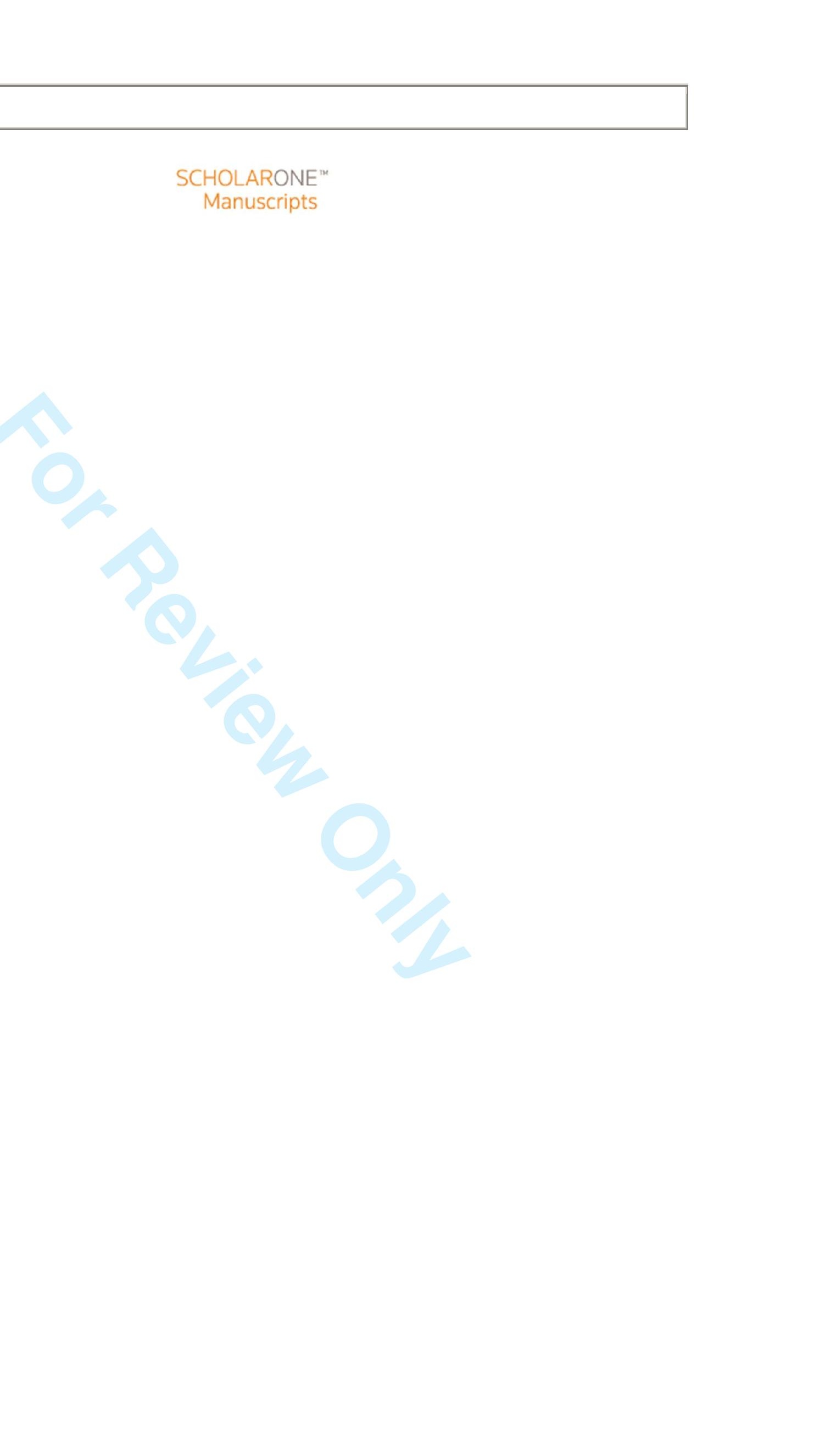

2

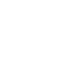

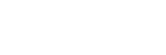

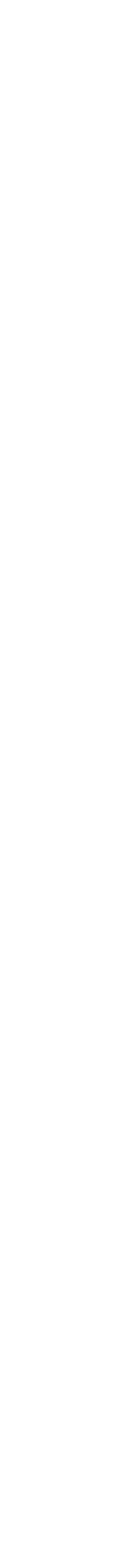

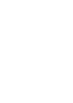

(2)

\section{1}


1 CONSISTENT EFFECTS OF CONSUMER SPECIES LOSS

2

3

4

5

6

7 Type of paper: Research paper

8

9 Corresponding author: Robert J. Mrowicki

10 Address:

11

12

13 Email:

14 Telephone:

15 Fax:

\section{ACROSS DIFFERENT HABITATS}

\author{
Robert J. Mrowicki, Christine A. Maggs and Nessa E. O’Connor
} School of Biological Sciences, Queen's University Belfast, UK

School of Biological Sciences, Queen's University Belfast, Medical Biology Centre, 97 Lisburn Road, Belfast, BT9 7BL, Northern Ireland, UK

rmrowicki01@qub.ac.uk

$+44(0) 2890972030$

+44(0)2890975877 
16

17

18

19

20

21

\section{Abstract:}

Our knowledge of the effects of consumer species loss on ecosystem functioning is limited by a paucity of manipulative field studies, particularly those that incorporate inter-trophic effects. Further, given the ongoing transformation of natural habitats by anthropogenic activities, studies should assess the relative importance of biodiversity for ecosystem processes across different environmental contexts by including multiple habitat types. We tested the contextdependency of the effects of consumer species loss by conducting a 15-month field experiment in two habitats (mussel beds and rock pools) on a temperate rocky shore, focussing on the responses of algal assemblages following the single and combined removals of key gastropod grazers (Patella vulgata, P. ulyssiponensis, Littorina littorea and Gibbula umbilicalis). In both habitats, the removal of limpets resulted in a larger increase in macroalgal richness than that of either L. littorea or G. umbilicalis. Further, by the end of the study, macroalgal cover and richness were greater following the removal of multiple grazer species compared to single species removals. Despite substantial differences in physical properties and the structure of benthic assemblages between mussel beds and rock pools, the effects of grazer loss on macroalgal cover, richness, evenness and assemblage structure were remarkably consistent across both habitats. There was, however, a transient habitat-dependent effect of grazer removal on macroalgal assemblage structure that emerged after three months, which was replaced by non-interactive effects of grazer removal and habitat after 15 months. This study shows that the effects of the loss of key consumers may transcend large abiotic and biotic differences between habitats in rocky intertidal systems. While it is clear that consumer diversity is a primary driver of ecosystem functioning, determining its relative importance across multiple contexts is necessary to understand the consequences of consumer species loss against a background of environmental change. 


\section{Introduction}

Global biodiversity loss continues to threaten the provision of ecosystem services and ultimately human wellbeing (Naeem et al. 2009, Hooper et al. 2012). Following more than two decades of intensive research, it is now accepted widely that declining biodiversity affects rates of ecosystem processes, such as resource capture and biomass production (Loreau et al. 2001, Cardinale et al. 2012, Gamfeldt et al. in press). In recognition of the complexity of biotic interactions within natural communities, an increasing number of biodiversityecosystem functioning studies have incorporated inter-trophic effects (Duffy et al. 2007). Despite this important move towards a multi-trophic perspective, our knowledge of the influence of consumer diversity loss on lower trophic levels is relatively incomplete (Duffy et al. 2007, Griffin et al. 2013). This is of particular concern, given that consumers generally have impacts that are disproportionate to their abundance and face a higher risk of extinction compared to producers (Duffy 2002).

Long-term field removal experiments are an effective means of characterising the effects of species loss within diverse natural assemblages (Díaz et al. 2003) and complement laboratory studies by revealing mechanisms that may not be manifested in smaller scale experiments conducted under more homogeneous conditions (Stachowicz et al. 2008). Further, as the ecological effects of biodiversity change are influenced by environmental context (Boyer et al. 2009, Crowe et al. 2011, Mrowicki and O'Connor in press), empirical studies that examine consumer diversity effects under a range of abiotic and biotic conditions (Griffin et al. 2009, O’Connor and Donohue 2013) will improve our ability to predict the consequences of species loss in the face of global environmental change involving multiple anthropogenic stressors (Harley et al. 2006). 
67 Coastal ecosystems are exposed to a range of anthropogenic impacts, which can result in 68 rapid declines in biodiversity and dramatic transformation or loss of habitat (Airoldi and Beck 69 2007). For example, on temperate rocky shores, overexploitation and pollution, coupled with the physiological and phenological responses of organisms to climate change, may lead to reduced densities or extinctions of key grazer species in certain localities (Thompson et al. 2002, Mieszkowska et al. 2005). Additionally, intertidal biogenic habitats, such as macroalgal and mussel beds on rocky substrata, have decreased in extent and structural complexity in many regions in response to various factors including physical disturbance and compromised water quality (Airoldi and Beck 2007). Changes in habitat complexity and heterogeneity alter interspecific interactions and the degree of resource partitioning among consumers, and can thus modify consumer diversity effects on resources (Hughes and Grabowski 2006, Griffin et al. 2009). In combination, these processes have the potential to shift the dynamic balance between producers and consumers and alter the functioning of coastal marine ecosystems 80 (Hawkins et al. 2009). The aim of this study was to determine whether the ecological consequences of consumer species loss vary with environmental context, in light of ongoing reductions in biodiversity and habitat homogenisation in coastal ecosystems. We quantified changes in macroalgal assemblages in response to individual and combined removals of common gastropod grazers, Patella vulgata, P. ulyssiponensis, Littorina littorea and Gibbula umbilicalis, in two different

87 habitats on an exposed north-east Atlantic rocky shore. Patellid limpets are key grazers in 88 European rocky intertidal habitats, and although their presence or absence often dominates the 89 effects of grazer assemblages on algal communities on emergent rock and in rock pools 90 (Hawkins and Hartnoll 1983, O’Connor and Crowe 2005, Coleman et al. 2006, Griffin et al. 
91 2010), the extent of their influence in other habitats, such as mussel beds, is less well known

92 (O’Connor and Crowe 2008). Further, the relative roles of these grazer species may vary

93 across different conditions, and the importance of changes in the richness versus identity of

94 these species is likely to increase with environmental heterogeneity (Griffin et al. 2009). To

95 examine the context-dependency of the roles of these key consumers, we performed

96 simultaneous grazer removals in mussel beds (on emergent rock) and in rock pools. These

97 two distinct habitats differ greatly with respect to the intensity and variability of a range of

98 abiotic stressors such as desiccation potential, temperature and wave disturbance.

99 Specifically, emergent rock habitats experience relatively greater fluctuations in abiotic

100 variables, but conditions can be more spatially variable among rock pools (Metaxas and

101 Scheibling 1993). At the same time, the physical structure afforded by either mussels or turf

102 algae (e.g. Corallina officinalis) enables diverse, yet divergent, biotic assemblages to persist

103 (Seed 1996, Kelaher 2002). Thus, owing to contrasting patterns of physical and biological

104 heterogeneity in mussel beds versus rock pools, the relative effects of grazer removal may

105 differ between these two habitats. Focussing on changes in macroalgal abundance, diversity

106 and assemblage structure, we hypothesised that: (1) there are species-specific consumer

107 identity effects, dominated by the influence of Patella spp. in both mussel beds and rock

108 pools; (2) the effects of the combined removal of multiple grazer species will exceed the

109 effects of removals of single species; and (3) these effects of grazer species loss will differ

110 between rock pools and mussel beds and vary according to experimental duration.

\section{Materials and methods}

113

114 Study site

115 
116 The experiment was conducted on an exposed rocky shore in Glashagh Bay, Fanad, Co.

117 Donegal, Ireland $\left(55.265^{\circ} \mathrm{N}, 7.675^{\circ} \mathrm{W}\right)$. The shore was characterised by a large, gently sloping

118 granitic platform, covered by a mosaic of patches of barnacles and macroalgae, typical of

119 exposed shores in the region (O’Connor and Crowe 2008, Mrowicki et al. 2014). Beds of

120 mussels (Mytilus spp.) were distributed patchily along the shore above mid-tidal level (2.0-

$1212.5 \mathrm{~m}$ above Chart Datum). Numerous discrete rock pools of varying area and depth were

122 present throughout the intertidal zone. Macroalgal assemblages associated with mussels

123 consisted of extensive epibiotic turfs of coarse red algae (mostly Gelidium spp.) interspersed

124 with ephemeral red (e.g. Porphyra umbilicalis) and green (e.g. Ulva intestinalis) algae. Small

125 clumps of brown algae (e.g. Fucus spiralis and F. serratus) were also found in and around the

126 mussel beds. The rock pools were dominated by turfs of upright calcareous algae (Corallina

127 officinalis), which supported an array of macroalgal species including fine (e.g. Polysiphonia

128 elongata and Ceramium rubrum) and coarse (e.g. Osmundea hybrida and Gelidium spp.)

129 branched red algae, ephemeral (e.g. U. compressa) and perennial (e.g. Codium tomentosum)

130 green algae and brown canopy algae (e.g. F. vesiculosus and Halidrys siliquosa). Encrusting

131 coralline algae ('Lithothamnia spp.') covered most of the remaining substratum. Thus, on this

132 shore, in addition to there being large differences in algal assemblage structure between the

133 two habitats, the diversity of algae was greater in rock pools compared to mussel beds (see

134 Results).

136 Grazing gastropods were common and widespread across the shore. The most conspicuous

137 species, which occurred in both mussel beds and rock pools, were the common and China

138 limpets (Patella vulgata and P. ulyssiponensis, respectively), common periwinkle (Littorina

139 littorea) and flat top shell (Gibbula umbilicalis). Although the two limpet species co-occurred

140 in both habitat types, particularly as newly settled juveniles in rock pools, $P$. ulyssiponensis 
141 adults were dominant in rock pools (Firth and Crowe 2008), whereas P. vulgata, which tends

142 to disperse out onto emergent rock, constituted the majority of limpets in mussel beds. Other

143 gastropod species, including L. saxatilis, L. obtusata and G. cineraria, were also present in

144 both habitats. Non-gastropod grazers such as chitons (e.g. Acanthochitona crinita) and

145 amphipods (e.g. Echinogammarus marinus) were found on the shore at lower densities.

147 Experimental design

148

149 Our experiment involved the single and combined removal of three genera of gastropod 150 grazer within each of the two habitat types (mussel beds and rock pools). We employed a

151 'subtractive' approach with no compensation for the reduction in biomass of particular 152 species by increasing that of the remaining species. Unlike a substitutive design, whereby

153 total grazer density would be equalised across treatments, such an approach avoids

154 confounding changes in intraspecific interactions with changes in interspecific interactions

155 among grazers (Byrnes and Stachowicz 2009). Further, instead of standardising species

156 densities across habitat types, we opted to mimic actual densities specific to mussel beds and

157 rock pools. Thus, we did not elicit potentially unsustainable experimental densities by

158 exceeding natural densities in either habitat (Harley 2006) and we minimised transplant-

159 induced stress or mortality of grazers, particularly limpets (Firth and Crowe 2010).

160 Importantly, although our design did not allow the effects of grazer removal and habitat type

161 to be separated from those of grazer density, incorporating (rather than eliminating) natural

162 variability in species densities was intended to enhance the realism of our study (Diaz et al.

1632003 ) with respect to this particular system.

164 
165 Within each of the two habitats, 20 plots $(35 \times 35 \mathrm{~cm})$ were located haphazardly around mid-

166 tidal level across approximately $100 \mathrm{~m}$ of shoreline, with a minimum separation between any

167 two plots of $1 \mathrm{~m}$. Mussel bed plots were positioned on well-drained, approximately

168 horizontal, substratum and incorporated $50.8 \pm 2.2 \%$ (mean \pm SE) mussel cover. Rock pool

169 plots were situated in separate pools of relatively similar area (range $\left.0.5-5.0 \mathrm{~m}^{2}\right)$ and depth $(<$

$17015 \mathrm{~cm}$ ) and included $46.5 \pm 4.2 \%$ cover of Corallina officinalis. By incorporating, rather than

171 controlling for, environmental heterogeneity such as inherent differences in habitat size (i.e.

172 mussel patch extent and rock pool volume), we aimed to enhance the relevance of this study

173 to variable natural systems.

174

175 Five grazer removal treatments were assigned randomly among the plots in each habitat type

$176(n=4)$ : one 'non-removal' treatment requiring the removal of no species; three 'single-

177 removal' treatments involving the removal of either Patella spp. (P. vulgata and $P$.

178 ulyssiponensis; hereafter Patella), Littorina littorea (hereafter Littorina) or Gibbula

179 umbilicalis (hereafter Gibbula); and one 'multi-removal' treatment, in which all three grazer

180 genera were removed. Owing to difficulties in the identification of $P$. vulgata and $P$.

181 ulyssiponensis, particularly juveniles and small adults, without causing substantial

182 disturbance, it was not possible to discriminate between limpet species. On rocky shores in

183 Ireland, adults of these two species tend to be segregated so that $P$. vulgata is more common

184 on emergent substrata than P. ulyssiponensis, which is more common in rock pools (Firth and

185 Crowe 2010). Further, there is the potential for contrasting functional roles of different limpet

186 species within the same habitat (Moore et al. 2007). Therefore, it is not possible here to

187 separate the effects of $P$. vulgata and $P$. ulyssiponensis across mussel beds and rock pools.

188 Instead, as both species are considered key grazers within their respective primary habitats

189 (Hawkins and Hartnoll 1983, O'Connor and Crowe 2005), the removal of Patella should be 
190 interpreted as the combined loss of putative strongly-interacting consumers in the case of both

191 mussel beds and rock pools. While it is possible here to make inferences regarding the

192 specific roles of Littorina and Gibbula, caution must be exercised when attributing the effects

193 of Patella removal, and their context-dependency, to particular species.

194

195 Experimental grazer abundances were derived from natural densities in mussel beds (Patella,

$19627.5 \pm 6.2 \mathrm{~m}^{-2}[$ mean $\pm \mathrm{SE} ; n=25]$; Littorina, $40.3 \pm 14.3 \mathrm{~m}^{-2}$ ) and rock pools (Patella, 201.6

$197 \pm 26.8 \mathrm{~m}^{-2} ;$ Littorina, $90.2 \pm 13.9 \mathrm{~m}^{-2}$; Gibbula, $9.6 \pm 2.9 \mathrm{~m}^{-2}$ ), adjusted to account for the high

198 proportion $(\sim 50 \%)$ of Patella juveniles $(<15 \mathrm{~mm})$ encountered in both habitat types.

199 Although not encountered within the area sampled by preliminary surveys, Gibbula was

200 present in mussel beds at low overall density, often in small aggregations adjacent to mussel

201 patches (R. J. Mrowicki, pers. obs.). Thus, experimental abundances were as follows: 3

202 Patella, 5 Littorina and 2 Gibbula in mussel bed plots; and 12 Patella, 11 Littorina and 2

203 Gibbula in rock pool plots. In a few cases, Littorina and Gibbula populations were

204 supplemented with additional individuals to meet target densities, although this was not

205 necessary for Patella. Treatments were maintained using stainless steel mesh cages $(35 \times$

$20635 \mathrm{~cm}$ area, $12 \mathrm{~cm}$ high) fixed to the substratum with stainless steel screws and washers. This

207 method was found to be most effective means of manipulating densities of mobile grazers

208 over extended time periods on this particular shore. The mesh size $(0.9 \mathrm{~mm}$ wire diameter,

$2094.17 \mathrm{~mm}$ aperture, $67 \%$ open area) of cages restricted the movement of the target grazer

210 species while allowing access to smaller mobile consumers and leaving plots open to

211 propagule supply.

212

213 To enable the detection of cage effects on experimental assemblages, an additional four plots

214 were established within each habitat and marked at opposite corners with stainless steel 
215 screws, thus remaining open to ambient densities of mobile organisms. Although there is the

216 potential for experimental artefacts to vary among treatments (Peterson and Black 1994,

217 Benedetti-Cecchi and Cinelli 1997), testing for interactions between cage effects and grazer

218 removal treatments would require the manipulation of grazer densities independently of the

219 use of cages, which is not feasible. Therefore, these uncaged control plots were designed to

220 test for the direct (e.g. shading and disruption of water flow) and indirect (e.g. altered grazer

221 behaviour) effects of cages on algal assemblages in the presence of ambient grazer densities

222 only, by comparing controls with non-removal caged plots. This approach follows previous

223 studies that have demonstrated no consequences of identical cages on the structure of

224 macroalgal assemblages in mussel beds and rock pools on similar shores (O'Connor and

225 Crowe 2005, O’Connor and Donohue 2013).

226

227 The experiment ran for 15 months starting in July 2011 and plots were surveyed at the

228 beginning of the experiment, after three months (October 2011) and after 15 months (October

229 2012). At each census, percent cover of macroalgal and sessile invertebrate species in each

230 plot was recorded by identifying species under 64 intersections of a $25 \times 25 \mathrm{~cm}$ quadrat.

231 Species present within the quadrat but not located under an intersection were recorded and

232 assigned a value of $1 \%$ each. The quadrat was positioned centrally within plots to avoid edge

233 effects. Total percent cover values often exceeded $100 \%$ owing to the multi-layered nature of

234 macroalgal communities. The numbers of grazer species within each plot were also recorded.

235 Treatments were maintained during monthly visits, at which times cages were also cleaned of

236 fouling species or debris to minimise cage effects on assemblages.

237

238 To determine whether percent cover served as a reliable proxy for macroalgal biomass, on the

239 final sampling date, a destructive sample of the central $25 \times 25 \mathrm{~cm}$ area in each experimental 
240 plot was taken to estimate biomass of each macroalgal species (excluding crustose corallines)

241 following drying to constant mass at $60^{\circ} \mathrm{C}$. Dry biomass values for Corallina officinalis were

242 multiplied by 0.2 to convert them to calcium carbonate-free estimates (Griffin et al. 2010).

243 There was a significant linear relationship between total dry biomass and total cover of

244 macroalgae (excluding crustose corallines), which differed between mussel beds and rock

245 pools (mussel beds: biomass $\left[\mathrm{g} \mathrm{m}^{-2}\right]=-2.07+4.42 \times \operatorname{cover}[\%], \mathrm{R}^{2}=0.929, P<0.001$; rock

246 pools: biomass $=-31.98+1.74 \times$ cover, $\left.\mathrm{R}^{2}=0.808, P<0.001\right)$.

247

248

249

250

251

252

253

254

255

256

257

258

259

260

261

262

263

264

Data analysis

For each sampling date separately, differences in macroalgal total cover, taxon richness (S) and evenness (Simpson's 1- $\lambda$ ) were tested using two-way factorial ANOVA involving habitat (fixed, 2 levels) and grazer removal treatment (fixed, 5 levels). Richness and evenness are complementary measures that are recommended for use in studies examining the consequences of biodiversity change (Altieri et al. 2009). Total algal cover was found to differ among grazer removal treatments across both habitats at the start of the experiment, although it was not possible to resolve these differences fully (Supplementary material Appendix 1 Table A1). Therefore, algal cover data were converted into the overall change in total cover to simplify interpretation. We used a priori planned contrasts to test for differences between the single-removal treatments and the multi-removal treatment but, given the limitations on making inferences regarding limpet identity, the variance explained by grazer removal was not partitioned further to isolate grazer 'identity' effects explicitly (Duffy et al. 2005). To test for cage effects, comparisons between caged non-removal plots and uncaged control plots were made for all variables. Prior to ANOVA, Shapiro-Wilk and Cochran's tests were used to check normality and homoscedasticity of data, respectively. In the case of total 
265 cover data for three months, transformation was unable to stabilise heterogeneous variances,

266 therefore results were interpreted with caution by reducing the limit for statistical significance

$267(\alpha=0.01)$. Student-Newman-Keuls $(\mathrm{SNK})$ tests were used to make post hoc comparisons

268 between levels of significant effects. Although SNK tests have the potential for excessive

269 Type I error rates when treatments fall into groups spaced widely apart (Day and Quinn

270 1989), which was generally not the case in the current study, a greater problem is the loss of

271 power resulting from the use of alternative procedures where SNK tests would otherwise be

272 suitable (Underwood 1997). Therefore, in this study, SNK tests were an appropriate means of

273 examining alternatives following the rejection of null hypotheses.

274

275 Permutational multivariate analysis of variance (PERMANOVA; McArdle and Anderson

276 2001, Anderson 2001) was used to test for effects of grazer treatments on macroalgal

277 assemblage structure in mussel beds and rock pools, separately for each sampling date, based

278 on the same model structure as the ANOVAs. Analyses were performed on zero-adjusted

279 Bray-Curtis dissimilarity matrices, i.e. via the addition of a dummy species with $1 \%$ cover to

280 all plots (Clarke et al. 2006), to deal with instances where no algae were recorded within

281 plots. Tests involved 9,999 permutations of residuals under the reduced model (Anderson and

282 ter Braak 2003). Differences among levels of significant factors were examined with post hoc

283 pairwise permutational $t$-tests. Where significant differences were found, similarity of

284 percentages analysis (SIMPER; Clarke 1993) was used to identify the algal taxa responsible

285 for differences in assemblage structure between treatment levels. To visualise differences in

286 macroalgal assemblage structure among treatment groups, nonmetric multidimensional

287 scaling (MDS) plots were produced. For all multivariate analyses, percent cover data were

$288 \log _{10}(x+1)$-transformed to reduce the influence of dominant algal species (Clarke and

289 Warwick 2001). All analyses were conducted in R (v3.0.1; R Development Core Team 2013), 
290 except for the PERMANOVAs, which were performed using the PERMANOVA+ add-on

291 (v1.0.3) in PRIMER (v6.1.13; PRIMER-E Ltd., Plymouth, UK).

292

293

Results

294

295 At the start of the experiment, macroalgal total cover, richness and evenness were greater in

296 rock pools than in mussel beds, and macroalgal assemblage structure differed between the two

297 habitats (Appendix 1 Table A1). After three months, there were still differences in algal

298 richness, evenness and assemblage structure between habitats (Fig. 1c,e; Table 1b-d).

299 Additionally, richness and evenness differed among grazer removal treatments, independently

300 of habitat (Fig. 1c,e; Table 1b,c). Across both mussel beds and rock pools, algal richness was

301 greater in the multi-removal treatment than in any other treatment (Fig. 1c). Although post

302 hoc tests were unable to resolve differences among the non-removal and single-removal

303 treatments fully, the removal of Patella appeared to result in an increase in algal richness

304 relative to the non-removal treatment across both habitats (Fig. 1c). Further, algal richness

305 was greater in the multi-removal treatment compared to the single-removal treatments (Table

306 1b). There also appeared to be an increase in algal evenness in the multi-removal treatment

307 compared to both the non-removal treatment and the Littorina single-removal treatment, but

308 post hoc tests were unable to resolve treatment differences fully (Fig. 1e).

310 After 15 months, the overall decline in total macroalgal cover was greater in rock pools than

311 in mussel beds (Fig. 1b; Table 1a). Again, macroalgal richness and evenness were found to be

312 greater in rock pools compared to mussel beds (Fig. 1d,f; Table 1b,c) and assemblage

313 structure differed between the two habitats (Table 1d). In addition to algal richness, total

314 cover change and assemblage structure were affected by grazer removal independently of 
315 habitat (Fig. 1b,d; Table 1a,b,d). The removal of Patella led to an increase in algal richness

316 relative to the non-removal treatment and the other two single-removal treatments (Fig. 1d).

317 Further, the multi-removal of all three grazers resulted in greater algal richness than any other

318 treatment (Fig. 1d) in addition to the mean of the single-removal treatments (Table 1b). The

319 multi-removal treatment led to an overall increase in total algal cover, which appeared to

320 differ significantly from the overall declines exhibited by the non-removal and the Patella and

321 Gibbula single-removal treatments, but post hoc tests were unable to resolve differences

322 among all treatments fully (Fig. 1b). In terms of algal evenness, there was no longer any

323 effect of grazer removal (Fig. 1f; Table 1c). The presence of cages reduced macroalgal

324 richness at three months (ANOVA; $F_{1,12}=5.83, P=0.033$; Fig. $1 \mathrm{c}$ ) and evenness at 15

325 months $\left(F_{1,12}=5.23, P=0.041\right.$; Fig. 1f; Appendix 2 Table A2)

326

327 There was a significant interaction between habitat and grazer removal treatments affecting

328 algal assemblage structure after three months, indicating that the responses of algal

329 assemblages to grazer removal differed between mussel beds and rock pools (Fig. 2a,c; Table

330 1d). Although post hoc tests were unable to resolve differences among treatments fully, they

331 suggested tentatively that, in mussel beds, the Patella single-removal and multi-removal

332 treatments resulted in a shift in algal assemblage structure relative to the Littorina and

333 Gibbula single-removal treatments (Fig. 2a; Appendix 3 Table A3). In contrast, in rock pools,

334 algal assemblage structure appeared to differ only between the non-removal and multi-

335 removal treatments (Fig. 2c; Appendix 3 Table A3). Algal assemblage structure also differed

336 between caged non-removal and uncaged control plots (Appendix 2 Table A2). After 15

337 months, there was no longer any interactive effect of habitat and grazer removal on algal

338 assemblage structure, indicating that the effects of grazer species loss were consistent between

339 mussel beds and rock pools (Fig. 2b,d; Table 1d). Across both habitats, there was a shift in 
340 algal assemblage structure in the Patella single-removal and multi-removal treatments relative

341 to all other treatments (Appendix 3 Table A3). This shift was driven consistently (i.e.

$\left.342 \bar{\delta}_{i} / \operatorname{SD}\left(\delta_{i}\right)>1\right)$ by a relative increase in Fucus vesiculosus $\left(\bar{\delta}_{i}=13.3 \%\right)$ and by relative

343 decreases in calcareous encrusting algae and Corallina officinalis, both of which were

344 primarily constituents of rock pool assemblages (Table 2). These changes were accompanied

345 by an increase in Cladophora rupestris and fucoid germlings across both habitats (Table 2).

\section{Discussion}

349 To advance our understanding of the consequences of species loss in the face of changing

350 environmental conditions, we must assess the relative contribution of biodiversity to

351 ecosystem processes across a range of contexts, while incorporating the complexity that

352 characterises natural ecosystems (Duffy et al. 2007, Cardinale et al. 2012). We performed

353 single and multiple removals of common grazer species, or groups of species, simultaneously

354 in mussel beds and rock pools, which represent two contrasting ecological contexts against a

355 background of natural environmental variability. The most striking aspect of our findings is

356 the overall consistency of responses to consumer loss across habitats over the duration of the

357 study, demonstrated by a general lack of interactions between habitat and grazer removal

358 treatments. While the effects of limpet removal cannot be attributed to individual species, the

359 loss of this group of putative key grazers, versus that of other grazer species, resulted in

360 similar relative changes to algal assemblages in mussel beds and rock pools. The fact that this

361 pattern emerged despite obvious differences in grazer densities and relative abundances

362 between habitats, in addition to initial differences in algal assemblages and environmental

363 conditions, suggests that consumer diversity (i.e. both identity and richness) is a major driver

364 of ecological processes in this system. In addition, the changes in the patterns of algal 
365 abundance and diversity over the course of the experiment and the transient habitat-dependent

366 response of algal assemblage structure emphasise that experimental duration is critical to the

367 interpretation of studies examining the effects of species loss across environmental contexts

368 (Cardinale et al. 2004, O'Connor and Crowe 2005, Stachowicz et al. 2008).

369

370 In both mussel beds and rock pools, algal total cover, species richness and evenness

371 underwent significant changes in response to grazer removal. In particular, the removal of

372 limpets led to a greater increase in algal richness than the removal of either Littorina littorea

373 or Gibbula umbilicalis. The key ecological role of patellid limpets, relative to other grazer

374 species, regulating the establishment of algae on emergent substrata and in tide pools on

375 European rocky shores is well known (Hawkins and Hartnoll 1983, O’Connor and Crowe

376 2005, Coleman et al. 2006, Griffin et al. 2010). The extent of their influence on algal

377 community dynamics in mussel beds, however, is perhaps less well appreciated (O'Connor

378 and Crowe 2008, Crowe et al. 2011). Our findings suggest that the relative functional roles of

379 limpets collectively, whether represented predominantly by Patella ulyssiponensis or by $P$.

380 vulgata, may be of similar importance in mussel beds compared to other habitats on rocky

381 shores, in spite of natural differences in total abundance.

382

383 Further, the differences among single-removal treatments suggest that other common grazer

384 species, even those present at higher natural densities, appear to be limited in their capacity to

385 compensate for the loss of limpets in mussel beds as well as rock pools (O'Connor and Crowe

386 2005, Griffin et al. 2010). Although our experiment allowed only for behavioural rather than

387 numerical compensation, previous research has demonstrated that even corresponding

388 increases in the abundance of L. littorea and G. umbilicalis are insufficient to compensate for

389 limpet removal in this system over similar timescales (O'Connor and Crowe 2005). While we 
390 cannot separate the effects of different limpet species, our results imply some degree of

391 functional complementarity between $P$. ulyssiponensis and P. vulgata at the scale of this study

392 owing to their spatial segregation between mussel beds and rock pools (Firth and Crowe

393 2010). Nonetheless, further experimentation is required to determine precisely how the

394 relative roles of these key species vary across habitats in which they coexist, particularly

395 because other closely related limpet species are known to have idiosyncratic effects on rocky

396 shore communities in this region (Moore et al. 2007).

397

398 A key finding of our study was that the removal of multiple grazer species led to a greater

399 increase in algal richness than did the removal of limpets alone, even though the single

400 removal of either Littorina littorea or Gibbula umbilicalis had no effect. This effect was

401 accompanied by a shift in algal assemblage structure in the limpet single-removal and multi-

402 removal treatments compared to all other treatments, which was driven largely by the

403 increased establishment and growth of fucoid macroalgae at the apparent expense of other

404 species. While consumer identity can be of overarching importance for the functioning of

405 marine ecosystems (O’Connor and Crowe 2005, Stachowicz et al. 2007), declines in

406 consumer diversity per se may lead to reduced top-down control owing to trait differentiation

407 among consumer species in terms of, for example, feeding preferences (Duffy 2002, Griffin et

408 al. 2009).

409

410 Alternatively, these patterns may have resulted from the reduction in grazer abundance

411 associated with the multi-removal treatment in our 'subtractive' experimental design, rather

412 than a reduction in grazer species richness. For example, the establishment of fucoid

413 macroalgae on rocky shores may occur only when grazer density falls below a certain

414 threshold (Jonsson et al. 2006). Indeed, the effects of grazer removal observed here may have 
415 been driven, at least in part, by differences in density among experimental treatments as

416 opposed to grazer identity or richness. Previous research has emphasised the importance of

417 density-dependent effects in regulating biodiversity-ecosystem functioning relationships (e.g.

418 Benedetti-Cecchi 2004, Maggi et al. 2009). To improve our understanding of complex, non-

419 linear effects of consumer species loss, future studies should aim to separate the importance

420 of consumer density from that of identity and richness, such as by incorporating density

421 explicitly as an additional treatment (Benedetti-Cecchi 2004, Byrnes and Stachowicz 2009).

422 While there were logistical constraints on the maximum number of treatments and replicates

423 in our study, incorporating (rather than eliminating) differences in grazer density between

424 treatments helped to maintain the relevance of our findings to species loss from natural

425 habitats in this system, at least for comparable spatial and temporal scales. Importantly, even

426 though the mechanisms underlying differences between the single-removal and multi-removal

427 treatments are unclear, our results suggest that, in both mussel beds and rock pools, the roles

428 of grazer species, or groups of species, depend on the presence or absence of other grazers

429 and, therefore, cannot be deduced from the effects of their removal in isolation.

430

431 Initially, grazer-driven changes in algal assemblage structure varied according to habitat.

432 Although the mechanisms driving this context-dependency remain unclear, there was some

433 indication of a greater overall response of algal assemblages, at least in terms of the number

434 of differences between treatment groups, in mussel beds compared to rock pools.

435 Nonetheless, the suggestion of a transient effect of habitat on community responses highlights

436 the importance of experimental duration in assessing the consequences of species loss from

437 complex ecosystems (O’Connor and Crowe 2005, Stachowicz et al. 2008). It is perhaps

438 surprising that habitat-dependent effects of grazer removal were not more common in our

439 study, given the contrasting patterns of environmental heterogeneity (Metaxas and Scheibling 
440 1993) and inherent differences in the abundance and structure of grazer and algal assemblages

441 between habitats (e.g. the difference in limpet densities between mussel beds and rock pools).

442 Instead, for the majority of responses measured in our study, the effects of grazer removal on

443 algal assemblages were remarkably consistent across habitats. Although this may mean that

444 the effects of consumer loss on algal communities were not mediated strongly by local-scale

445 variability between habitats on the same shore, other processes such as variation in

446 recruitment or disturbance regimes may play a greater role over larger scales (Jenkins et al.

447 2005, Mrowicki et al. 2014). For example, divergent effects of grazer removal may emerge

448 even in similar habitats on different rocky shores separated by kilometres (Crowe et al. 2011).

449 While the consequences of changing diversity are expected to be more apparent over larger

450 spatial and temporal scales (Cardinale et al. 2004, Stachowicz et al. 2008), it is less clear how

451 the importance of abiotic factors in determining the effects of species loss varies across

452 multiple scales.

453

454 There are some caveats that should be considered when attempting to extend our findings to

455 rocky intertidal systems in general. First, the presence of experimental cages appeared to 456 influence the structure of algal assemblages, either directly, via shading or hydrodynamic 457 disruption, or indirectly, by altering the movement of grazers or providing habitat for other 458 consumers. Owing to the nature of the study system, cages were the most suitable means of 459 manipulating grazer populations over the timescale of the experiment, and it was not possible

460 to test whether cage effects interacted with grazer removal treatment. The fact that clear

461 differences emerged among caged treatments despite substantial environmental variability

462 within and between habitats, however, suggests that the observed effects of grazer species

463 loss may indeed be representative of unmanipulated, 'real world' communities within this

464 system. Second, it was found that total algal cover was not equivalent across treatments at the 
465 start of the experiment, which may have influenced the responses of algal assemblages to 466 grazer removal. The initial pattern of algal cover, however, did not correspond with that 467 observed later in the experiment, in addition to the differences (or lack thereof) in richness 468 and evenness between treatments. Again, this suggests that grazer removal was the most 469 important force driving changes in algal assemblages over the course of the experiment.

470 While it is important to exercise caution in relating the results of manipulative studies to real 471 world scenarios, field-based removal experiments are useful for understanding how complex 472 ecosystems respond to species loss, serving as much-needed tests of fundamental ecological 473 theory (Díaz et al. 2003, Stachowicz et al. 2008, Gamfeldt et al. in press).

475 In conclusion, our results demonstrate that the relative effects of the loss of key groups of 476 consumers can transcend different physical and biological conditions between habitats.

477 Specifically, limpets, which comprised predominantly Patella vulgata in mussel beds and $P$. 478 ulyssiponensis in rock pools, were of comparable importance, in relation to Littorina littorea 479 and Gibbula umbilicalis, in the maintenance of the abundance, diversity and structure of algal 480 assemblages. We found clear effects of grazer removal despite inherent environmental 481 heterogeneity both between and within habitats, which provides compelling evidence of the 482 overarching importance of these grazer species across the contexts examined in this study. On 483 European rocky shores, community processes and energy transfer are driven by the spatial 484 and temporal dynamics of algae, which in turn are regulated largely by the activities of such 485 mobile grazers (Hawkins and Hartnoll 1983). Therefore, although the applicability of our 486 findings to other rocky shore habitats remains to be tested, shifts in the dynamics of algal 487 communities resulting from changing compositions and densities of consumer populations 488 may have important consequences across multiple environmental contexts in coastal 489 ecosystems. Overall, while it is clear that biodiversity plays a fundamental role in driving 
490 ecosystem functioning, our ability to predict the ecological consequences of species loss will

491 be enhanced by determining the range of relevant contexts and scales over which it has the

492 greatest influence, particularly against the current background of global environmental change

493 (Hooper et al. 2012).

494

495 Acknowledgements

496

497 We thank S. J. Hawkins, J. D. R. Houghton and four anonymous reviewers for useful

498 comments that improved this manuscript substantially. We are grateful to M. Alexander, R.

499 Burgundy, N. Carey, C. Magill, E. Nolan, C. Reddin, E. Strain, R. Thomson and S. Vye for

500 assistance in the field. This study was completed as part of a $\mathrm{PhD}$ funded by the Department

501 for Employment and Learning Northern Ireland.

502

503 References

504

505 Airoldi, L. and Beck, M. W. 2007. Loss, status and trends for coastal marine habitats of

506 Europe. - Oceanogr. Mar. Biol. Annu. Rev. 45: 345-405.

507 Altieri, A. H. et al. 2009. Consumers control diversity and functioning of a natural marine

$508 \quad$ ecosystem. - PLoS One 4: e5291.

509 Anderson, M. J. 2001. A new method for non-parametric multivariate analysis of variance. -

$510 \quad$ Austral Ecol. 26: 32-46.

511 Anderson, M. J. and ter Braak, C. J. F. 2003. Permutation tests for multi-factorial analysis of

512 variance. - J. Stat. Comput. Sim. 73: 85-113.

513 Benedetti-Cecchi, L. 2004. Increasing accuracy of causal inference in experimental analyses

514 of biodiversity. - Func. Ecol. 18: 761-768. 
515 Benedetti-Cecchi, L. and Cinelli, F. 1997. Confounding in field experiments: direct and

516 indirect effects of artifacts due to the manipulation of limpets and macroalgae. - J. Exp.

$517 \quad$ Mar. Biol. Ecol. 209: 171-184.

518 Boyer, K. E. et al. 2009. Biodiversity effects on productivity and stability of marine

519 macroalgal communities: the role of environmental context. - Oikos 118: 1062-1072.

520 Byrnes, J. E. and Stachowicz, J. J. 2009. The consequences of consumer diversity loss:

521 different answers from different experimental designs. - Ecology 90: 2879-2888.

522 Cardinale, B. J. et al. 2004. Effects of species diversity on the primary productivity of

523 ecosystems: extending our spatial and temporal scales of inference. - Oikos 104: 437-

$524 \quad 450$.

525 Cardinale, B. J. et al. 2012. Biodiversity loss and its impact on humanity. - Nature 486: 59-

$526 \quad 67$.

527 Clarke, K. R. 1993. Non-parametric multivariate analyses of changes in community structure.

$528 \quad$ - Aust. J. Ecol. 18: 117-143.

529 Clarke, K. R. and Warwick, R. 2001. Change in marine communities: an approach to

530 statistical analysis and interpretation, $2^{\text {nd }}$ edition. - PRIMER-E Ltd., Plymouth, UK.

531 Clarke, K. R. et al. 2006. On resemblance measures for ecological studies, including

532 taxonomic dissimilarities and a zero-adjusted Bray-Curtis coefficient for denuded

533 assemblages. - J. Exp. Mar. Biol. Ecol. 330: 55-80.

534 Coleman, R. A. et al. 2006. A continental scale evaluation of the role of limpet grazing on

$535 \quad$ rocky shores. - Oecologia 147: 556-564.

536 Crowe, T. P. et al. 2011. Interactive effects of losing key grazers and ecosystem engineers

537 vary with environmental context. - Mar. Ecol. Prog. Ser. 430: 223-234.

538 Day, R. W. and Quinn, G. P. 1989. Comparisons of treatments after an analysis of variance in 539 ecology. - Ecol. Monogr. 59: 433-463. 
540 Díaz, S. et al. 2003. Functional diversity revealed by removal experiments. - Trends Ecol.

$541 \quad$ Evol. 18: 140-146.

542 Duffy, J. E. 2002. Biodiversity and ecosystem function: the consumer connection. - Oikos 99: $543 \quad 201-219$.

544 Duffy, J. E. et al. 2005. Ecosystem consequences of diversity depend on food chain length in 545 estuarine vegetation. - Ecol. Lett. 8: 301-309.

546 Duffy, J. E. et al. 2007. The functional role of biodiversity in ecosystems: incorporating $547 \quad$ trophic complexity. - Ecol. Lett. 10: 522-538.

548 Firth, L. B. and Crowe, T. P. 2008. Large-scale coexistence and small-scale segregation of

$549 \quad$ key species on rocky shores. - Hydrobiologia 614: 233-241.

550 Firth, L. B. and Crowe, T. P. 2010. Competition and habitat suitability: small-scale 551 segregation underpins large-scale coexistence of key species on temperate rocky shores. 552 Oecologia 162: 163-174.

553 Gamfeldt, L. et al. In press. Marine biodiversity and ecosystem functioning: what's known 554 and what's next? - Oikos. DOI: 10.1111/oik.01549

555 Griffin, J. N. et al. 2009. Spatial heterogeneity increases the importance of species richness 556 for an ecosystem process. - Oikos 118: 1335-1342.

557 Griffin, J. N. et al. 2010. Consumer effects on ecosystem functioning in rock pools: roles of 558 species richness and composition. - Mar. Ecol. Prog. Ser. 420: 45-56.

559 Griffin, J. N. et al. 2013. Effects of predator richness on prey suppression: a meta-analysis. $560 \quad$ Ecology 94: 2180-2187.

561 Harley, C. D. G. 2006. Effects of physical ecosystem engineering and herbivory on intertidal 562 community structure. - Mar. Ecol. Prog. Ser. 317: 29-39.

563 Harley, C. D. G. et al. 2006. The impacts of climate change in coastal marine systems. - Ecol. $564 \quad$ Lett. 9: 228-241. 
565 Hawkins, S. J. and Hartnoll, R. G. 1983. Grazing of intertidal algae by marine invertebrates. -

566 Oceanogr. Mar. Biol. Annu. Rev. 21: 195-282.

567 Hawkins, S. J. et al. 2009. Consequences of climate-driven biodiversity changes for

568 ecosystem functioning of North European rocky shores. - Mar. Ecol. Prog. Ser. 396: 245569259.

570 Hooper, D. U. et al. 2012. A global synthesis reveals biodiversity loss as a major driver of 571 ecosystem change. - Nature 486: 105-108.

572 Hughes, A. R. and Grabowski, J. H. 2006. Habitat context influences predator interference

573 interactions and the strength of resource partitioning. - Oecologia 149: 256-264.

574 Jenkins, S. R. et al. 2005. Regional scale differences in the determinism of grazing effects in 575 the rocky intertidal. - Mar. Ecol. Prog. Ser. 287: 77-86.

576 Jonsson, P. R. et al. 2006. Interactions between wave action and grazing control the 577 distribution of intertidal macroalgae. - Ecology 87: 1169-1178.

578 Kelaher, B. P. 2002. Influence of physical characteristics of coralline turf on associated 579 macrofaunal assemblages. - Mar. Ecol. Prog. Ser. 232: 141-148.

580 Loreau, M. et al. 2001. Biodiversity and ecosystem functioning: current knowledge and future $581 \quad$ challenges. - Science 294: 804-808.

582 Maggi, E. et al. 2009. Effects of changes in number, identity and abundance of habitat583 forming species on assemblages of rocky seashores. - Mar. Ecol. Prog. Ser. 381: 39-49.

584 McArdle, B. H. and Anderson, M. J. 2001. Fitting multivariate models to community data: a 585 comment on distance-based redundancy analysis. - Ecology 82: 290-297.

586 Metaxas, A. and Scheibling, R. E. 1993. Community structure and organization of tidepools. 587 Mar. Ecol. Prog. Ser. 98: 187-198. 
588 Mieszkowska, N. et al. 2005. Marine biodiversity and climate change: assessing and

589 predicting the influence of climatic change using intertidal rocky shore biota. Scottish

590 Natural Heritage Commissioned Report No. 202 (ROAME No. F01AA402).

591 Moore, P. et al. 2007. Effects of grazer identity on the probability of escapes by a canopy-

592 forming macroalga. - J. Exp. Mar. Biol. Ecol. 344: 170-180.

593 Mrowicki, R. J. and O’Connor, N. E. In press. Wave action modifies the effects of consumer

594 diversity and warming on algal assemblages. - Ecology. DOI: 10.1890/14-0577.1

595 Mrowicki, R. J. et al. 2014. Does wave exposure determine the interactive effects of losing

596 key grazers and ecosystem engineers? - J. Exp. Mar. Biol. Ecol. 461: 416-424.

597 Naeem, S. et al. 2009. Biodiversity, Ecosystem Functioning, and Human Wellbeing: An

$598 \quad$ Ecological and Economic Perspective. - Oxford Univ. Press.

599 O’Connor, N. E. and Crowe, T. P. 2005. Biodiversity loss and ecosystem functioning:

600 distinguishing between number and identity of species. - Ecology 86: 1783-1796.

601 O'Connor, N. E. and Crowe, T. P. 2008. Do mussel patches provide a refuge for algae from 602 grazing gastropods? - J. Mollus. Stud. 74: 75-78.

603 O’Connor, N. E. and Donohue, I. 2013. Environmental context determines multi-trophic

604 effects of consumer species loss. - Glob. Change Biol. 19: 431-440.

605 Peterson, C. H. and Black, R. 1994. An experimentalist's challenge: when artifacts of

606 intervention interact with treatments. - Mar. Ecol. Prog. Ser. 111: 289-297.

607 R Development Core Team 2013. R: A language and environment for statistical computing.

608 in press. R Foundation for Statistical Computing, Vienna, Austria.

609 Seed, R. 1996. Patterns of biodiversity in the macro-invertebrate fauna associated with mussel

610 patches on rocky shores. - J. Mar. Biol. Assoc. UK 76: 203-210.

611 Stachowicz, J. J. et al. 2007. Understanding the effects of marine biodiversity on communities 612 and ecosystems. - Annu. Rev. Ecol. Evol. Syst. 38: 739-766. 
613 Stachowicz, J. J. et al. 2008. Complementarity in marine biodiversity manipulations:

614 reconciling divergent evidence from field and mesocosm experiments. - P. Natl. Acad.

615 Sci. USA 105: 18842-18847.

616 Thompson, R. C. et al. 2002. Rocky intertidal communities: past environmental changes,

617 present status and predictions for the next 25 years. - Environ. Conserv. 29: 168-191.

618 Underwood, A. J. 1997. Experiments in Ecology: Their Logical Design and Interpretation

619 Using Analysis of Variance. - Cambridge Univ. Press.

620

621 Supplementary material (Appendix oik.XXXX at

$622<$ www.oikosjournal.org/readers/appendix >). Appendix 1-3. 
Table 1. ANOVAs and PERMANOVA testing effects of habitat (mussel beds versus rock pools) and grazer removal treatments (non-removal;

627 included as covariates. Significant $P$-values are highlighted in bold.

\begin{tabular}{|c|c|c|c|c|c|c|c|c|c|c|c|c|c|}
\hline \multirow[b]{2}{*}{ Source of variation } & \multirow[b]{2}{*}{ DF } & \multicolumn{3}{|c|}{ (a) Total cover change ${ }^{\dagger}$} & \multicolumn{3}{|c|}{ (b) Richness } & \multicolumn{3}{|c|}{ (c) Evenness } & \multicolumn{3}{|c|}{ (d) Assemblage structure } \\
\hline & & MS & $F$ & $P$ & MS & $F$ & $P$ & $\overline{\mathrm{MS}}$ & $F$ & $P$ & MS & Pseudo- $F$ & $P$ \\
\hline \multicolumn{14}{|l|}{ Three months: } \\
\hline Habitat, $\mathrm{H}$ & 1 & 23.93 & 0.07 & 0.789 & 455.62 & 236.69 & $<0.001$ & 0.62 & 13.13 & 0.001 & 64400.00 & 93.74 & $<0.001$ \\
\hline Grazer removal, Gr & 4 & 479.77 & 1.46 & 0.240 & 19.29 & 10.02 & $<0.001$ & 0.16 & 3.41 & 0.021 & 2155.10 & 3.14 & $<0.001$ \\
\hline Single vs. multi & 1 & 802.15 & 2.43 & 0.129 & 37.50 & 19.48 & $<0.001$ & 0.18 & 3.78 & 0.061 & 3086.90 & 3.91 & 0.006 \\
\hline $\mathrm{H} \times \mathrm{Gr}$ & 4 & 62.87 & 0.19 & 0.941 & 3.81 & 1.98 & 0.123 & 0.06 & 1.29 & 0.295 & 1771.70 & 2.58 & $<0.001$ \\
\hline Residual & 30 & 329.59 & & & 1.92 & & & 0.05 & & & 686.99 & & \\
\hline \multicolumn{14}{|l|}{15 months: } \\
\hline $\mathrm{H}$ & 1 & 1329.00 & 6.13 & 0.019 & 250.00 & 100.00 & $<0.001$ & 0.20 & 5.45 & 0.026 & 56223.00 & 75.95 & $<0.001$ \\
\hline $\mathrm{Gr}$ & 4 & 1510.80 & 6.96 & $<0.001$ & 37.96 & 15.19 & $<0.001$ & 0.09 & 2.60 & 0.056 & 3770.90 & 5.09 & $<0.001$ \\
\hline Single vs. multi & 1 & 3711.80 & 17.11 & $<0.001$ & 82.51 & 33.00 & $<0.001$ & 0.12 & 3.42 & 0.074 & 7052.70 & 7.74 & $<0.001$ \\
\hline $\mathrm{H} \times \mathrm{Gr}$ & 4 & 199.60 & 0.92 & 0.465 & 0.69 & 0.28 & 0.892 & 0.02 & 0.63 & 0.644 & 1090.10 & 1.47 & 0.089 \\
\hline Residual & 30 & 216.90 & & & 2.50 & & & 0.04 & & & 740.24 & & \\
\hline
\end{tabular}

${ }^{\dagger}$ Transformation of data for three months was unable to stabilise heterogeneous variances. 
629 Table 2. SIMPER analysis of algal assemblage structure across both habitats (mussel beds 630 and rock pools) after 15 months, comparing the treatments involving the removal of Patella 631 (the Patella single-removal treatment and the multi-removal treatment) to all other grazer 632 removal treatments collectively (the non-removal treatment and the Littorina and Gibbula

633 single-removal treatments). $\bar{\delta}_{i} / \mathrm{SD}\left(\delta_{i}\right)=$ average species contribution to group dissimilarity

634 divided by standard deviation of contributions; $\bar{\delta}_{i} \%=$ percent contribution of species to 635 overall between-group dissimilarity. Calculations are based on $\log _{10}(x+1)$-transformed species 636 abundances. Only the most important species $\left(\bar{\delta}_{i}>3 \%\right)$ are shown.

\begin{tabular}{|c|c|c|c|c|}
\hline \multirow[b]{2}{*}{ Species } & \multicolumn{2}{|c|}{ Mean cover $(\%)$} & \multirow[b]{2}{*}{$\bar{\delta}_{i} / \mathrm{SD}\left(\delta_{i}\right)$} & \multirow[b]{2}{*}{$\bar{\delta}_{i} \%$} \\
\hline & $\begin{array}{c}\text { Patella and } \\
\text { multi-removal } \\
\text { treatments }\end{array}$ & $\begin{array}{l}\text { Other removal } \\
\text { treatments }\end{array}$ & & \\
\hline Fucus vesiculosus & 11.91 & 0.50 & 1.50 & 13.32 \\
\hline Lithothamnia spp. & 18.62 & 27.60 & 1.04 & 12.69 \\
\hline Corallina officinalis $^{\dagger}$ & 30.66 & 19.79 & 1.08 & 12.59 \\
\hline F. spiralis & 6.15 & 0.07 & 0.87 & 8.82 \\
\hline Ceramium shuttleworthianum & 1.37 & 2.17 & 0.86 & 6.97 \\
\hline Gelidium pusillum & 2.37 & 1.44 & 0.98 & 5.44 \\
\hline Cladophora rupestris & 2.37 & 1.58 & 1.15 & 5.18 \\
\hline Fucus sp. (juvenile) & 0.95 & 0.04 & 1.05 & 4.51 \\
\hline Asparagopsis armata ${ }^{\dagger}$ & 0.58 & 1.84 & 0.90 & 3.73 \\
\hline Ulva intestinalis & 0.88 & 0.13 & 0.55 & 3.39 \\
\hline Polysiphonia fucoides ${ }^{\dagger}$ & 0.94 & 1.45 & 0.86 & 3.30 \\
\hline
\end{tabular}

${ }^{\dagger}$ Recorded in rock pools only; ${ }^{\dagger}$ Recorded in mussel beds only. 


\section{Figure legends}

639

640 Figure 1. Mean (+ or - SE) macroalgal $(a, b)$ total cover change, $(c, d)$ species richness and 641 (e,f) evenness for different grazer removal treatments (None = non-removal; $\mathrm{P}, \mathrm{L}$ and $\mathrm{G}=$ 642 single-removal of Patella, Littorina and Gibbula, respectively; PLG = multi-removal of all 643 three grazers) in mussel beds (shaded bars, M) and rock pools (open bars, R), after (a,c,e) 644 three and (b,d,f) 15 months. ' $\mathrm{M}<>>\mathrm{R}$ ' indicates a significant difference between habitats ( ${ }^{*} P$ $645<0.05, * * P<0.01, * * * \mathrm{P}<0.001)$, based on ANOVA results. Letters denote grazer removal 646 groups (i.e. across both levels of habitat) that are not significantly different $(P \geq 0.05)$, based 647 on post hoc SNK tests, to illustrate significant main effects of grazer removal independently 648 of habitat.

649

650 Figure 2. Non-metric MDS ordinations of macroalgal assemblages for different grazer

651 removal treatments $($ None $=$ non-removal; $\mathrm{P}, \mathrm{L}$ and $\mathrm{G}=$ single-removal of Patella, Littorina

652 and Gibbula, respectively; PLG = multi-removal of all three grazers) in (a,b) mussel beds and 653 (c,d) rock pools after $(\mathrm{a}, \mathrm{c})$ three and $(\mathrm{b}, \mathrm{d}) 15$ months, based on $\log _{10}(x+1)$-transformed species 654 abundances. Care should be taken when interpreting plots for which stress $>0.2$ (Clarke 655 1993). 


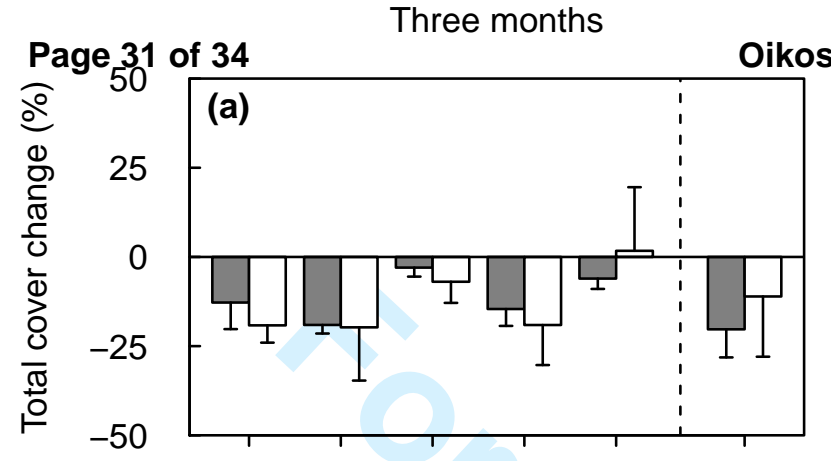

None P L G PLG Control

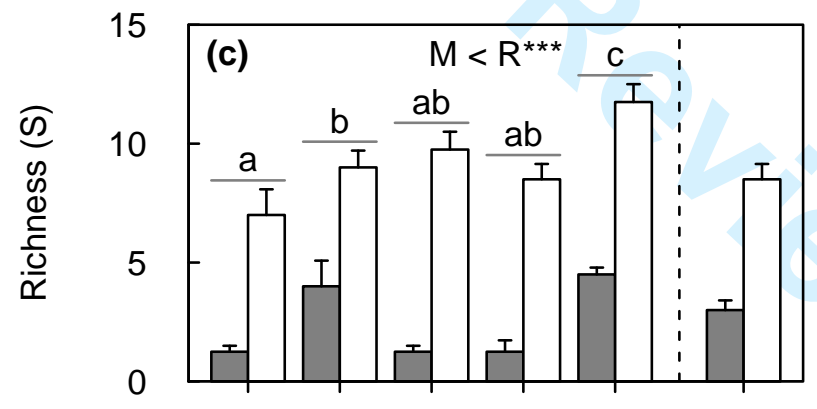

None P L G PLG Control

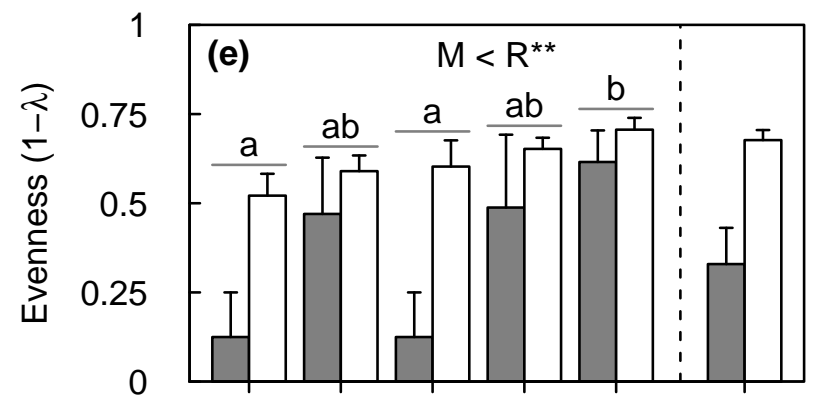

None P L G PLG Control Grazers removed

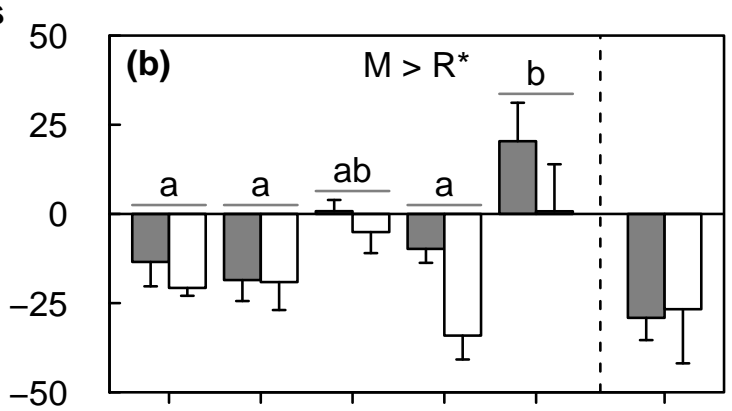

None P L G PLG Control

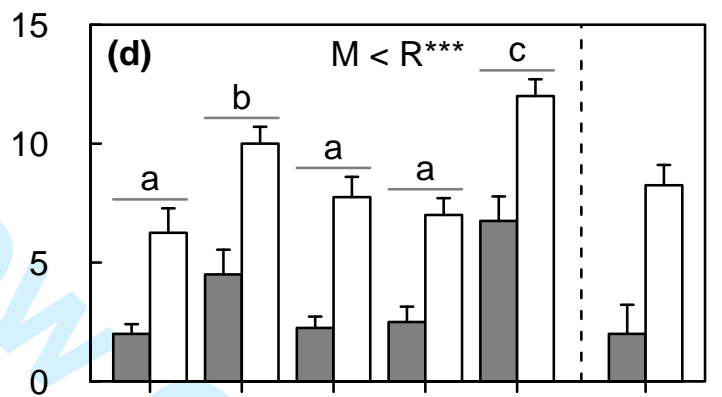

None P L G PLG Control

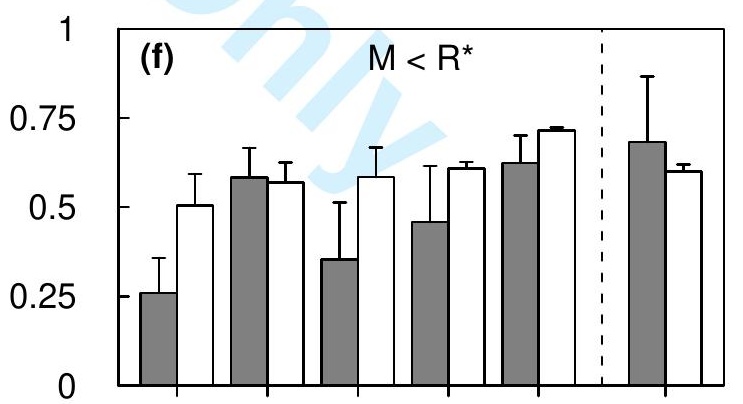

None P L G PLG Control Grazers removed 


\title{
CONSISTENT EFFECTS OF CONSUMER SPECIES LOSS ACROSS DIFFERENT HABITATS
}

\author{
Robert J. Mrowicki, Christine A. Maggs \& Nessa E. O’Connor
}

Appendix 1. Results of tests for differences in algal assemblages among treatments at the start of the experiment.

Table A1. ANOVAs and PERMANOVA testing effects of habitat (mussel beds versus rock pools) and grazer removal treatments (non-removal; single-removals of Patella, Littorina and Gibbula; multi-removal of all three grazers) on macroalgal (a) total cover, (b) taxonomic richness, (c) Simpson's evenness $(1-\lambda)$ and (d) assemblage structure at the start of the experiment in July 2011 . Significant $P$-values are highlighted in bold.

\begin{tabular}{|c|c|c|c|c|c|c|c|c|c|c|c|c|c|}
\hline \multirow[t]{2}{*}{ Source of variation } & \multirow[t]{2}{*}{$\mathrm{DF}$} & \multicolumn{3}{|c|}{ (a) Total cover } & \multicolumn{3}{|c|}{ (b) Richness } & \multicolumn{3}{|c|}{ (c) Evenness ${ }^{\dagger}$} & \multicolumn{3}{|c|}{ (d) Assemblage structure } \\
\hline & & MS & $F$ & $P$ & MS & $F$ & $P$ & MS & $F$ & $P$ & MS & Pseudo- $F$ & $P$ \\
\hline Grazer removal, Gr & 5 & 816.00 & 3.21 & $0.017^{\ddagger}$ & 4.88 & 2.44 & 0.053 & 0.05 & 1.54 & 0.201 & 1407.00 & 1.56 & 0.073 \\
\hline $\mathrm{H} \times \mathrm{Gr}$ & 5 & 294.00 & 1.16 & 0.350 & 2.43 & 1.22 & 0.321 & 0.02 & 0.70 & 0.630 & 1307.30 & 1.45 & 0.114 \\
\hline
\end{tabular}

${ }^{\dagger}$ Data were squared to improve normality and stabilise heterogeneous variances; ${ }^{\dagger}$ Student-Newman-Keuls post hoc tests were unable to resolve differences fully among grazer removal treatments. 


\section{CONSISTENT EFFECTS OF CONSUMER SPECIES LOSS ACROSS DIFFERENT HABITATS}

Robert J. Mrowicki, Christine A. MAGgS \& NeSSA E. O’CONNOR

Appendix 2. Results of tests for the effects of experimental cages on algal assemblages.

Table A2. ANOVAs and PERMANOVA testing the effects of habitat (mussel beds versus rock pools) and the presence of cages (caged nonremoval treatment versus uncaged control treatment) on macroalgal (a) total cover change, (b) taxonomic richness, (c) Simpson's evenness (1- $\lambda$ ) and (d) assemblage structure, after three (October 2011) and 15 (October 2012) months. Significant $P$-values are highlighted in bold.

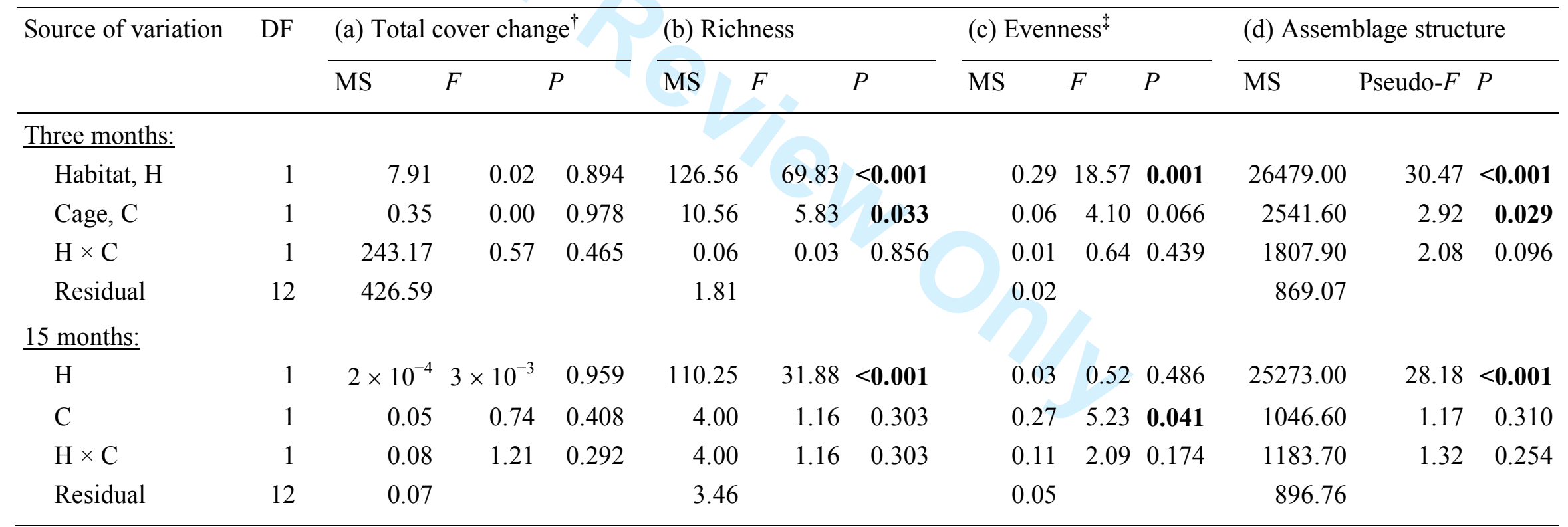

${ }^{\dagger}$ Data for 15 months were squared to stabilise heterogeneous variances; ${ }^{\star}$ Data for three months were squared to improve non-normality. 


\title{
CONSISTENT EFFECTS OF CONSUMER SPECIES LOSS ACROSS DIFFERENT HABITATS
}

\author{
Robert J. Mrowicki, Christine A. MagGs \& Nessa E. O’ConNor
}

Appendix 3. Results of post hoc tests for differences in algal assemblage structure among experimental treatments.

Table A3. PERMANOVA post hoc pairwise tests of differences in algal assemblage structure among grazer removal treatments (None = non-removal; $\mathrm{P}, \mathrm{L}$ and $\mathrm{G}=$ single-removal of Patella, Littorina and Gibbula, respectively; PLG = multi-removal of all three grazers), (a) after three months, for mussel beds and rock pools separately, and (b) 15 months, across both habitats. Significant $P$-values are highlighted in bold.

\begin{tabular}{|c|c|c|c|c|c|c|}
\hline \multirow[b]{3}{*}{ Comparison } & \multicolumn{4}{|c|}{ (a) Three months ${ }^{\dagger}$} & \multirow{2}{*}{\multicolumn{2}{|c|}{$\begin{array}{l}\text { (b) } 15 \text { months } \\
\text { Both habitats }\end{array}$}} \\
\hline & \multicolumn{2}{|c|}{ Mussel beds } & \multicolumn{2}{|c|}{ Rock pools } & & \\
\hline & $t$ & $P$ & $t$ & $P$ & $t$ & $P$ \\
\hline None vs. P & 1.38 & 0.161 & 1.31 & 0.178 & 1.88 & 0.012 \\
\hline None vs. L & 1.07 & 0.339 & 1.48 & 0.100 & 1.14 & 0.280 \\
\hline None vs. G & 1.08 & 0.337 & 1.36 & 0.152 & 0.88 & 0.555 \\
\hline None vs. PLG & 1.59 & 0.099 & 2.44 & 0.011 & 3.38 & $<0.001$ \\
\hline P vs. L & 2.47 & 0.016 & 1.31 & 0.180 & 2.27 & 0.003 \\
\hline P vs. G & 2.14 & 0.022 & 0.97 & 0.443 & 2.00 & 0.009 \\
\hline P vs. PLG & 1.18 & 0.272 & 1.31 & 0.176 & 1.49 & 0.054 \\
\hline L vs. G & 0.68 & 0.686 & 1.21 & 0.233 & 1.03 & 0.407 \\
\hline L vs. PLG & 2.98 & 0.007 & 1.17 & 0.273 & 3.37 & $<0.001$ \\
\hline G vs. PLG & 2.34 & 0.012 & 1.54 & 0.078 & 3.41 & 0.001 \\
\hline
\end{tabular}

${ }^{\dagger}$ Owing to the low number of possible permutations $(\leq 35)$, Monte Carlo asymptotic $P$-values, rather than standard permutational $P$-values, are presented. 